\title{
A Role for the High-Density Lipoprotein Receptor SR-B1 in Synovial Inflammation via Serum Amyloid-A
}

Ronan Hugh Mullan, Jennifer McCormick, Mary Connolly, Barry Bresnihan, Douglas James Veale, and Ursula Fearon

From the Department of Rheumatology, Education and Research Centre, St Vincent's University Hospital, Dublin, Ireland

Acute phase apoprotein Serum Amyloid A (A-SAA), which is strongly expressed in rheumatoid arthritis synovial membrane (RA SM), induces angiogenesis, adhesion molecule expression, and matrix metalloproteinase production through the G-coupled receptor FPRL-1. Here we report alternative signaling through the high-density lipoprotein receptor scavenger receptor-class B type 1 (SR-B1). Quantitative expression/localization of SR-B1 in RA SM, RA fibroblast-like cells (FLCs), and microvascular endothelial cells (ECs) was assessed by Western blotting and immunohistology/fluorescence. A-SAA-mediated effects were examined using a specific antibody against SR-B1 or amphipathic $\alpha$-Helical Peptides (the SR-B1 antagonists L-37pA and D-37pA), in RA FLCs and ECs. Adhesion molecule expression and cytokine production were quantified using flow cytometry and ELISA. SR-B1 was strongly expressed in the RA SM lining layer and endothelial/perivascular regions compared with osteoarthritis SM or normal control synovium. Differential SR-B1 expression in RA FLC lines $(n=5)$ and ECs correlated closely with A-SAA, but not tumor necrosis factor $\alpha$-induced intercellular adhesion molecule- 1 upregulation. A-SAA-induced interleukin- 6 and -8 production was inhibited in the presence of anti-SR-B1 in human microvascular endothelial cells and RA FLCs. Moreover, D-37pA and L-37pA inhibited A-SAA-induced vascular cell adhesion molecule- 1 and intercellular adhesion molecule expression from ECs in a dose-dependent manner. As SR-B1 is expressed in RA synovial tissue and mediates A-SAA-induced pro-inflammatory pathways, a better understanding of A-SAA-mediated inflammatory pathways may lead to novel treatment strategies for RA. (Am J Pathol 2010, 176:1999-2008; DOI: 10.2353/ajpath.2010.090014)
Rheumatoid arthritis (RA) is a chronic progressive autoimmune disease characterized by proliferation of the synovial membrane (SM), which leads to degradation of articular cartilage and subchondral bone. Normal SM consists of a monolayer of synoviocytes including fibroblast-like cells (FLCs) and macrophage-like synoviocytes, which produce a proteoglycan-rich synovial fluid to lubricate the joint and provide nutrition to the avascular cartilage. A critical early event in synovial inflammation is angiogenesis, where new blood vessels develop from existing blood vessels and act as a conduit for the delivery of nutrition and invading immune cells into the joint. Recruitment of immune cells into the joint is mediated by tissue expression of chemokines and by expression of cell surface adhesion molecules such as intercellular adhesion molecule-1 (ICAM-1) and vascular cell adhesion molecule-1 (VCAM-1), which selectively recruit mononuclear cells through their integrin receptors ligands. ${ }^{1-3}$ In RA, activation of the SM transforms the lining layer into a hyperplastic tumor-like 'pannus' composed primarily of activated FLCs, macrophage-like synoviocytes, and lymphocytes, which through self perpetuating and persistent pro-inflammatory activation, are capable of destroying adjacent articular cartilage and bone..-6.

Acute phase serum amyloid A (A-SAA) is a highlyconserved acute phase apoprotein whose serum levels increase up to a 1000 fold within hours of an inflammatory stimulus. ${ }^{7}$ Unlike other acute phase proteins, which are synthesized primarily in the liver as part of the systemic acute phase response, A-SAA is also markedly expressed at local sites of tissue inflammation. A-SAA is also known to be present at high levels in wound repair and in cancer tissues. ${ }^{8}$ A-SAA, at normal serum levels,

Supported by a grant from the Health Research Board of Ireland. There are no affiliations with any organization or entity that have a direct financial or personal interest in the subject matter or materials discussed in this article.

D.J.V. and U.F. contributed equally to this work and are joint senior authors.

Accepted for publication December 7, 2009

Supplemental material for this article can be found on http://ajp. amjpathol.org

Address reprint requests to Dr. Ursula Fearon, Education and Research Centre, St. Vincent's University hospital, Elm Park, Dublin 4, Ireland. E-mail: Ursula.fearon@ucd.ie. 
associates with high-density lipoprotein (HDL) forming a heterogenous HDL population containing both A-SAA and apolipoprotein A-1 (ApoA-1). ${ }^{9}$ During the inflammatory response, however, A-SAA is dramatically elevated in serum ( 1 to $1000 \mu \mathrm{g} / \mathrm{ml}$ ), at which levels A-SAA displaces ApoA-1 and saturates HDL resulting in high levels of free circulating A-SAA. ${ }^{10,11}$ Our group has demonstrated a strong correlation between serum A-SAA and disease activity in RA. ${ }^{12}$ Furthermore, we and others have demonstrated that A-SAA is produced by synovial FLCs and articular chondrocytes, where it is a powerful inducer of matrix metalloproteinases in these cells in vitro. ${ }^{13-15}$ A-SAA induces the secretion of pro-inflammatory cytokines tumor necrosis factor- $\alpha$ (TNF- $\alpha$ ), interleukin- $1 \beta$ (IL$1 \beta$ ), and interleukin-8 (IL-8) and acts as a chemoattractant for human monocytes, neutrophils and $T$ cells. ${ }^{16,17}$ A-SAA has high affinity for the extracellular matrix components laminin and fibronectin and has been shown to enhance leukocyte binding to extracellular matrix through a $\beta 1$ integrin dependent mechanism. ${ }^{18,19}$ We have demonstrated increased ICAM-1/NCAM-1 expression, increased endothelial cell (EC) migration, EC tubule formation, and matrix metalloproteinase 1 production in response to A-SAA in RA FLCs and ECs with an effect equipotent to TNF- $\alpha$ and $\mathrm{IL}-1 \beta .{ }^{17}$ These studies together indicate that A-SAA may play a primary pathogenic role locally in joint destruction and mediating cartilage destruction.

A-SAA is known to bind to a formyl peptide receptor-like 1 (FPRL-1), a seven-transmembrane G protein-coupled receptor. Through FPRL-1, A-SAA interacts with a diverse array of exogenous and endogenous ligands in the inflammatory process including leukocyte migration, IL-8 induction, and matrix metalloproteinase production. ${ }^{16,20-22} \mathrm{We}$, and others, have shown overexpression of A-SAA and its receptor FPRL-I in RA SM. ${ }^{13,14,16}$ Lipoxin (LXA4) A4, an ecosanoid metabolite with anti-inflammatory actions, has recently been shown to inhibit the pro-inflammatory actions of A-SAA by competitive binding with FPRL-1 and differential regulation of the transcription factor nuclear factorkappa B (NF- $\mathrm{B}$ ). ${ }^{16,22}$ Recent evidence has demonstrated alternative A-SAA binding to and signaling through the HDL receptor human scavenger receptor class $B$ type 1 (SRB1). ${ }^{23}$ SR-B1, also known CD36 and LIMPII analogous-1 (CLA-1), is the human orthologue of rodent SR-B1, which functions as a membrane bound receptor for $\mathrm{HDL} .{ }^{24} \mathrm{~A}-\mathrm{SAA}$ binding to SR-B1 expressed on a monocyte cell line, induces chemokine production, activates extracellular signalregulated kinases 1/2 (ERK1/2) and p38 mitogen activated protein kinases, a process that may involve cholesterol efflux. ${ }^{23,25}$ A-SAA binding and signaling through SR-B1 have been shown to be inhibited by co-incubation with ApoA-1 or a synthetic mimetic peptide of ApoA-1 known as L-37PA in a dose-dependent manner. ${ }^{23}$ Ligand binding of L-37PA to SR-B1 has also been shown to block the pro-inflammatory cytokine response to LPS in THP-1 cells, although to date this effect has not been demonstrated for intact ApoA-1. ${ }^{26}$

In this study we provide further evidence of a pathophysiological role of A-SAA in driving the pro-inflammatory response in RA through SR-B1. We demonstrate strong expression of SR-B1 in RA SM and differential expression of SR-B1 on RA FLC lines that correlate with
A-SAA responsiveness. Furthermore we demonstrate that the pro-inflammatory actions of A-SAA in RA FLCs and human microvascular endothelial cells (HMVECs) can be blocked both by specific antibodies directed against SR-B1 and by synthetic mimetic peptides of ApoA-1. These findings support a novel role for A-SAA as an important mediator of synovial inflammation and suggest a novel strategy for A-SAA as a potential future therapeutic target in the treatment of inflammation through modulation of SR-B1.

\section{Materials and Methods}

\section{Patient Recruitment and Arthroscopy}

Patients with RA ( $n=8)$, according to the criteria of the American College of Rheumatology, ${ }^{27}$ or osteoarthritis $(\mathrm{OA} ; n=5)$ were recruited from rheumatology outpatient clinics at St. Vincent's University Hospital along with one normal healthy control subject. RA patients had clinically active disease including at least one inflamed knee joint. When compared with OA patients, RA patients had statistically higher serum levels of systemic inflammation as measured by $\mathrm{C}$-reactive protein $(18 \pm 16$ RA vs $5 \pm 2$ $\mathrm{OA}, \mathrm{mmol} / \mathrm{L} P<0.05)$ and erythrocyte sedimentation rate $(29 \pm 7 \mathrm{RA}$ vs $18 \pm 7 \mathrm{OA}, \mathrm{mm} / \mathrm{hr}, P<0.05$, mean \pm SEM). There was no difference in the age range of patients when RA ( $59 \pm 4 \mathrm{yrs}$ ) was compared with OA ( $55 \pm$ $24 \mathrm{yrs})$. After approval by the institutional ethics committee, all patients gave written informed consent, before a day case arthroscopy procedure under local anesthetic. Arthroscopy of an inflamed knee joint using a 2.7-mmdiameter needle telescope (Stortz, Tuttlingen, Germany) was performed and biopsies of inflamed SM were obtained under direct visualization as previously described. ${ }^{3}$ Synovial biopsies were obtained from seven RA patients. SM Biopsies were snap frozen in OCT, foil wrapped, and stored at $-70^{\circ} \mathrm{C}$. Cryostat sections $7 \mu \mathrm{m}$ thick were cut, dried overnight at $37^{\circ} \mathrm{C}$, and stored at $-70^{\circ} \mathrm{C}$ and used for immunohistochemistry. Further biopsies were placed in medium and used to isolate RA primary synovial fibroblasts as outlined below.

\section{Isolation and Culture of RA FLC Cell Lines}

Synovial biopsies were digested using $1 \mathrm{mg} / \mathrm{ml}$ collagenase (Worthington Biochemical, Freehold, NJ) in RPMI (Gibco-BRL, Paisley, UK) for 4 hours at $37^{\circ} \mathrm{C}$ in humidified air with $5 \%$ CO2. Dissociated cells were grown to confluence in RPMI, 10\% fetal calf serum (FCS; GibcoBRL), $10 \mathrm{ml}$ of $1 \mathrm{mmol} / \mathrm{L}$ HEPES (Gibco-BRL), penicillin (100 units $/ \mathrm{ml}$ ), streptomycin (100 units $/ \mathrm{ml}$ ), and fungizone $(0.25 \mu \mathrm{g} / \mathrm{ml})$ before passaging. Cells were morphologically homogeneous RA FLCs and were used for experiments between passages 4 and 8 .

\section{Isolation and Culture of HMVECs}

Dermal-derived HMVECs (Clonetics, San Diego, CA) grown in endothelial basal medium supplemented with $5 \%$ FCS, $0.5 \mathrm{ml}$ human epidermal growth factor, $0.5 \mathrm{ml}$ 
hydrocortisone, $0.5 \mathrm{ml}$ gentamicin, $0.5 \mathrm{ml}$ bovine brain extract (Clonetics) were used for experiments between passages 3 and 8 .

\section{Immunohistochemical Expression of SR-B1 Receptor in RA Synovial Tissue}

For histological analysis SM samples were placed in cryopreservative embedding media OCT compound (Tissue Tek, Sakura, Finetek, Europe BV, Zoeterwoude, The Netherlands) and immediately frozen in liquid nitrogen. Sections $(7 \mu \mathrm{m})$ were cut using a cryostat and placed on glass slides coated with 2\% 3-amino-propyl-triethoxysilane (Sigma-Aldrich Ireland Ltd, Dublin, Ireland) dried overnight at room temperature and then stored at $-80^{\circ} \mathrm{C}$ until required for staining. Tissue sections were allowed to reach room temperature, fixed in acetone for 10 minutes, air-dried, and allowed to reach room temperature. Tissue sections were then incubated for 1 hour at room temperature with normal blocking serum (Vectastain Elite Kit, Vector Laboratories Ltd, Peterborough, UK). The slides were incubated with avidin for 15 minutes, rinsed, and then incubated with biotin for 15 minutes. The slides were then incubated for 1 hour with the primary mouse monoclonal antibody for SR-B1 (BD Biosciences) at 1:50 to 1:100 dilutions at room temperature. Secondary antibody (anti-mouse; Vectastain) was prepared and added to the relevant sections and incubated for 1 hour. The secondary antibody was washed off and the slides were incubated with avidin-biotin-peroxidase complex solution for 30 minutes and incubated for 6 minutes with 3,3' -diaminobenzidine and counterstained in hemotoxylin stain for 1 minute. The sections were mounted using DPX (BDH Laboratory Supplies, Poole, UK). For negative control, isotype-matched nonimmune IgG was included. Sections were assessed using light microscopy. Sections were specifically examined for evidence of SR-B1 expression at the synovial lining layer where active destruction of articular cartilage and bone occurs, and on vascular ECs and perivascular areas where angiogeneisis and leukocyte recruitment occur. SR-B1 expression was analyzed by two blinded operators using an established semiquantitative scoring method ranging from 0 to $4(0=$ no staining, $1=<25 \%, 2=25 \%$ to $50 \%, 3=50 \%$ to $75 \%, 4=>75 \%$ staining). ${ }^{28,29}$ Sections were scored for lining layer and sublining layer expression separately.

\section{Immunofluorescent Staining for SR-B1 in HMVECs and RA FLCs}

SR-B1 expression in resting HMVECs and RA FLCs was detected by immunoflourescence microscopy. HMVECs and RA FLCs were grown to $20 \%$ confluence in eight-chamber culture slides (Becton Dickenson) in full-strength endothelium basal medium (Clonetics). The cells were then fixed in $4 \%$ paraformaldehyde for 20 minutes and blocked using $1 \%$ casein solution for 20 minutes. Slides were then incubated with a primary antibody for SR-B1 (mouse monoclonal; 1:100, BD Bio- sciences) and an appropriate IgG isotype-matched control for 1 hour in a humidified chamber. Chamber slides were then washed in PBS for 5 minutes and then incubated with a Cy2 conjugated secondary antibody (Sigma; 1:200 dilution) for 30 minutes. Slides were washed in PBS for 5 minutes and counterstained with DAPI nuclear stain (Sigma) (1:1000 dilution) for 20 minutes. The cells were then mounted with antifade (Molecular Probes, Eugene, OR) and assessed by immunofluorescence microscopy ( $\times 40$ magnification).

\section{SR-B1 Expression in Primary Cell Lines by Western Blot}

For measurement of SR-B1 by Western blot, RA FLC lines $(n=5)$ or HMVECs $1 \times 10^{6} /$ well were seeded into six-well plates in RPMI, 10\% FCS for 48 hours. Cells were then washed twice in PBS and lysed in $100 \mu \mathrm{l}$ SDS sample buffer $(62.5 \mathrm{mmol} / \mathrm{L}$ Tris/ $\mathrm{HCl}, \mathrm{pH} 6.8,10 \%$ glycerol, $2 \%$ SDS, 5\% mercaptoethanolm, and $0.0013 \%$ Bromophenol Blue). Lysates were fractionated by SDS/PAGE, 10\% acrylamide gels and transferred on to a nitrocellulose membrane (BioTrace $₫ N T$, Pensacola, FL). The membrane was washed for 15 minutes $3 \times$ in wash buffer (PBS, 0.1\% TWEEN) before being blocked with 5\% milk powder in PBA overnight at $5^{\circ} \mathrm{C}$. After washing $3 \times$ in washing buffer, the membrane was incubated overnight at $5^{\circ} \mathrm{C}$ with purified monoclonal mouse IgG antibodies for SR-B1 (BD Biosciences) at a 1:500 dilution in $10 \mathrm{ml}$ primary blocking buffer containing PBS, 0.1\% Tween 20, 2.5\% milk powder. The primary antibody was then aspirated off and the nitrocellulose membrane washed $3 \times$ in wash buffer. The membrane was then incubated with an enhanced chemiluminescent substrate anti-mouse IgG horseradish peroxidase-linked whole antibody (from sheep) (Amersham Biosciences) at 1:2000 dilution in $10 \mathrm{ml} \mathrm{PBS,} \mathrm{0.1 \%} \mathrm{Tween,} \mathrm{2.5 \%}$ milk powder. A rainbow molecular marker (GE Health care, Cork, Ireland) with molecular weights of 35, 50, 75, 105, and $160 \mathrm{kDa}$ was used to quantify the correct molecular weight for SR-B1 on the nitrocellulose membrane. Chemiluminescence was achieved using an enhanced chemiluminescent substrate (Pierce, Rockford II), which reacts with horseradish-peroxidase-conjugated secondary antibodies. The light emitted was captured by exposure to X-ray film for 30 seconds. Quantitation of SR-B1 expression using densitometry analysis was normalized against $\beta$-actin staining by Western blot using a primary incubation step as described above using a mouse mAb $\beta$-actin (Sigma) in $10 \mathrm{ml}$ PBS, 0.1\% Tween 20, 2.5\% milk powder.

\section{SR-B1 Mediates A-SAA-Induced IL-6 and IL-8 Production in HMVECs and RA FLCS}

To assess the role of SR-B1 on A-SAA-induced IL-6, expression HMVECs $(n=6)$ and an additional 4 primary RA FLC lines were pre-incubated with purified IgG antimouse anti-SR-B1 antibody (10 $\mu \mathrm{g} / \mathrm{ml}$; BD Biosciences) or an isotype matched (IgG1) anti-mouse control (R\&D systems) for 2 hours before stimulation with A-SAA (10 
$\mu \mathrm{g} / \mathrm{ml}$; Peprotech, Rocky Hill, $\mathrm{NJ}$ ) or $\mathrm{H}_{2} \mathrm{O}$ vehicle control for 24 hours. The SR-B1 antibody stock solution (250 $\mu \mathrm{g} / \mathrm{ml}, \leq 0.09$ sodium azide) when diluted for this experiment contained a final concentration of sodium azide of $0.0036 \%$. A control experiment where HMVECs were incubated with A-SAA $(10 \mu \mathrm{g} / \mathrm{ml})$ in the presence or absence of $0.0036 \%$ sodium azide was performed to eliminate any possible inhibitory effect of sodium azide on cytokine production. A-SAA stimulation increased IL-6 levels from $27.9 \pm 0.5$ unstimulated to $1096 \pm 197 \mathrm{pg} / \mathrm{ml}$ after A-SAA stimulation $(n=3)$. No inhibition of IL-6 was observed in the presence of sodium azide $(1196 \pm 277$ $\mathrm{pg} / \mathrm{ml}$; Supplemental Figure S1, see http://ajp.amjpathol. org). A-SAA preparations were $>98 \%$ purity by SDSPAGE and HPLC analyses, and had endotoxin levels of $\leq 1 \mathrm{EU}$ confirmed by Limulus assay (BioWhittaker, Walkersville, MD). Supernatants were harvested and IL-6 and IL-8 levels were measured by ELISA (R\&D systems). To demonstrate that SR-B1 antagonists, such as the amphipathic $\alpha$-helical peptides block A-SAA-induced pro-inflammatory pathways, HMVECs were incubated with ASAA in the presence or absence of L-37pA \& D-37pA, all of which have been shown to bind to SR-B1 $1^{26}$ and which inhibit the effects of A-SAA on a SR-B1 overexpressing HeLa cell line. ${ }^{23}$ The SR-B1 ligands L-37pA and D-37pA are class $A$ helical amphipathic peptides produced by a solid phase procedure as previously reported ${ }^{30}$ Peptide sequences were described previously. ${ }^{31} \mathrm{~A}$ third peptide L3D-37pA, which contains triple D-amino acid substitutions to abolish the helical structure of the molecule, has previously been shown not to possess cellular effects. ${ }^{26}$ The purity of the three peptides was $>95 \%$ by HPLC analysis. All three peptides were a kind donation from Alexander Bocharov (Department of Laboratory Medicine, National Institute of Health, Bethesda, MD). To directly assess the effect of L-37pA, D-37pA, and L3D37pA on A-SAA-induced ICAM-1 and VCAM-1 expression, HMVECs $(n=6)$ and RA FLC lines $(n=3)$ were grown to confluence at a cell count of $5 \times 10^{4}$ in 12-well plates (Falcon, Franklin Lakes, NJ) in RPMI 10\% FCS before being pre-incubated for 2 hours in serum-reduced (1\%) medium. Cells were pre-incubated with L-37pA, D-37pA, or L3D-37pA for 1 hour at concentrations 2.5, 5, or $10 \mu \mathrm{g} / \mathrm{ml}$ before the addition of A-SAA to a final concentration of $0.5 \mu \mathrm{g} / \mathrm{ml}$. The control peptide L3D-37pA was used as negative control $(n=6)$. Cells were transferred to fluorescence-activated cell sorting tubes (Becton Dickinson, Franklin Lakes, NJ) and incubated with 0.3 $\mu \mathrm{g} / \mathrm{ml}$ of phycoerythrin-conjugated monoclonal mouse anti-ICAM-1 (Becton Dickenson), anti-VCAM-1 (Becton Dickenson), or an appropriate isotype-lgG matched control (Becton Dickinson) for 30 minutes at $4^{\circ} \mathrm{C}$. Cells were then washed twice in PBS containing $3 \%$ bovine serum albumin, $0.2 \%$ sodium azide (PBA), fixed in PBA, $1 \%$ paraformaldehyde, and analyzed by flow cytometry (FACS) using a FACScan flow cytometer (Becton Dickinson) and Lysis II software. Cell viability studies using ethidium bromide-acridine orange uptake showed $>95 \%$ of cells remained viable for the duration of the experiment, demonstrating that the results were not a result of cytotoxicity.

\section{Statistical Analysis}

Data are expressed as the mean \pm SEM, unless otherwise stated. Groups were compared using the Wilcoxon signed rank or analysis of variance tests; $P$ values $<0.05$ were considered statistically significant.

\section{Results}

\section{SR-B1 Is Expressed on RA Synovial Tissue}

To identify whether the novel A-SAA receptor SR-B1 is expressed in inflamed RA synovial tissue, immunohistochemical analysis was performed on tissue sections of synovial biopsy specimens harvested under direct visualization from the inflamed joints of RA patients by needle arthroscopy. SR-B1 protein was detected in six of eight RA tissue samples examined by immunohistochemistry, with minimal expression found in two of five OA tissue sections with no expression demonstrated in normal synovium (Figure 1). Distinct SR-B1-positive staining was observed in the synovial vascular ECs and in cells accumulating in both the synovial lining and sublining layers of
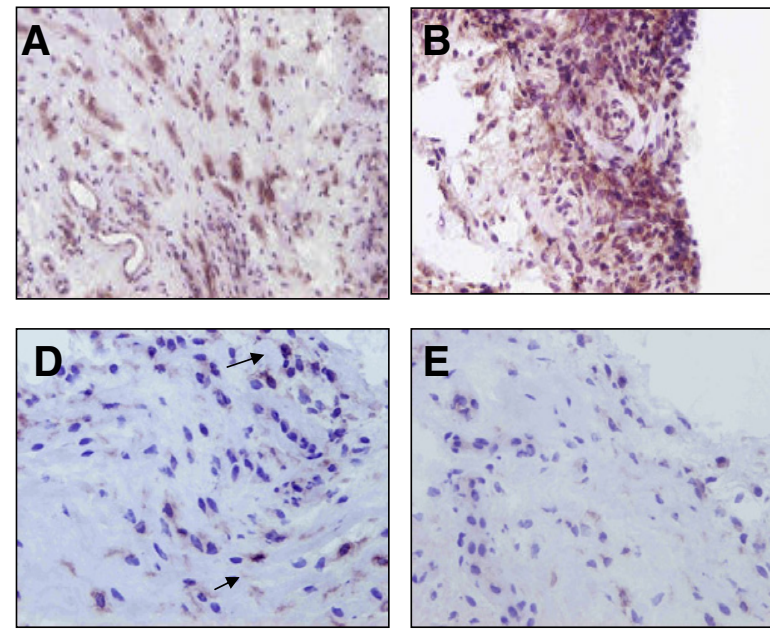
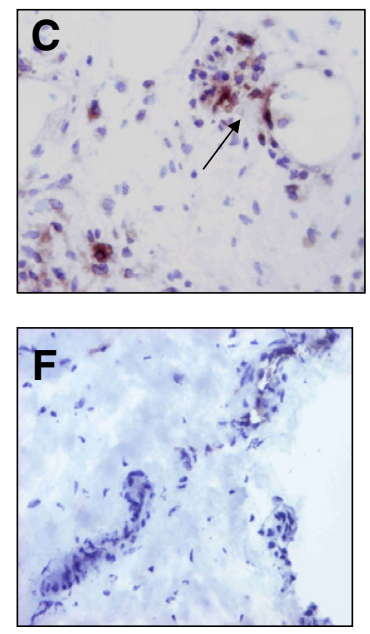

Figure 1. SR-B1 protein expression in inflamed RA synovial tissue. RA synovial tissue sections from three representative RA patients $(\mathbf{A}-\mathbf{C})$, two OA patients ( $\mathbf{D}$ and $\mathbf{E}$ ), and one healthy control (F) were stained with an antibody to SR-B1. A brown stain indicates cells positive for SR-B1 expression. In RA patients SR-B1 expression was demonstrated on (A) synovial intimal blood vessels, (B) the synovial lining and sublining layers, (C) and in synovial vascular ECs (shown by arrow). Minimal staining is seen in OA tissue (D and $\mathbf{E}$ ) and normal healthy control tissue (F). 

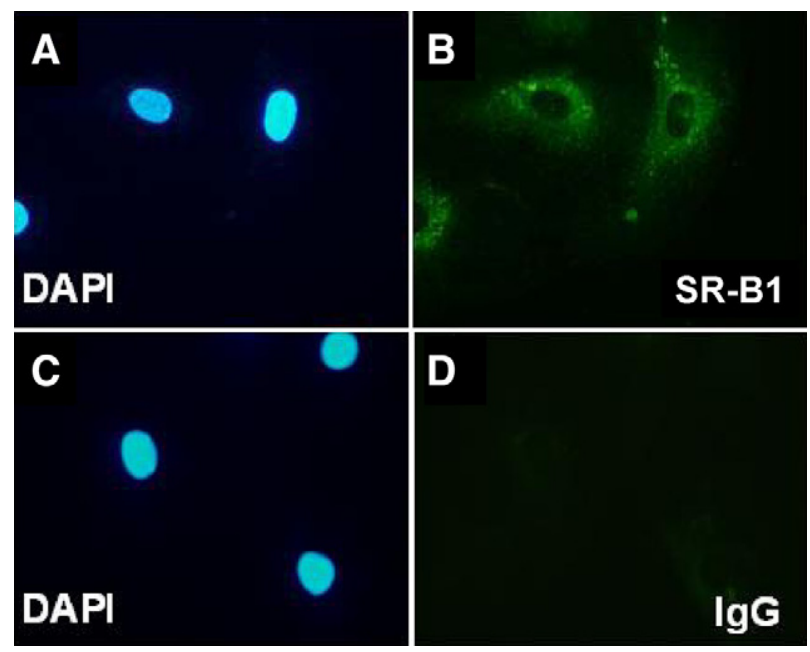

Figure 2. SR-B1 staining on resting HMVECs by immunoflourescence. DAPI nuclear stain (A) with corresponding cytoplasmic SR-B1 localized to the same cells (B). DAPI staining (C) with IgG control (D).

RA SM (Figure 1, A-C) compared with OA tissue, which showed minimal staining (Figure 1, D and E) and normal tissue (Figure 1F). Semiquantitative scoring demonstrated increased expression in both the lining layer and sublining of patients with RA compared with OA (1.1 \pm $0.52 \mathrm{RA}$ versus $0.5 \pm 0.5 \mathrm{OA}$, lining layer; $1.4 \pm 0.72 \mathrm{RA}$ versus $0.8 \pm 0.53 \mathrm{OA}$, sublining). No expression was observed in normal tissue. Immunostaining with an igG isotype-matched control was completely negative in all samples examined (data not shown).

\section{SR-B1 Expression on HMVECs by Direct Immunoflourescence}

To confirm the presence of SR-B1 on vascular ECs, SR-B1 immunoflourescence was performed on resting HMVECs grown on culture slides $(n=3)$. Strong staining for SR-B1 was seen on all HMVECs tested. Staining for IgG control was completely negative (Figure 2, A-D).

\section{SR-B1 Expression on RA FLCs and HMVECs by Western Blot}

To investigate whether the presence of SR-B1 in RA synovial tissue is due, at least in part, to expression on $R A$ FLCs or ECs, SR-B1 expression was demonstrated on five separate RA FLC lines and on HMVECs. A representative Western blot is shown in Figure 3. SR-B1 expression was demonstrated in all five RA FLC lines studied and on HMVECs (Figure 3A). Variable expression of SR-B1 expression was shown between cell lines and was more marked on RA FLCs than on HMVECs.

The erosive and invasive nature of primary RA FLC lines in vitro have previously been shown to explain different rates of radiographical progression seen between RA patients in vivo. ${ }^{32}$ Furthermore, high levels of expression of ICAM-1 on RA FLCs are associated with a more aggressive and invasive phenotype. ${ }^{33}$ To establish whether a relationship exists between SR-B1 expression and re-
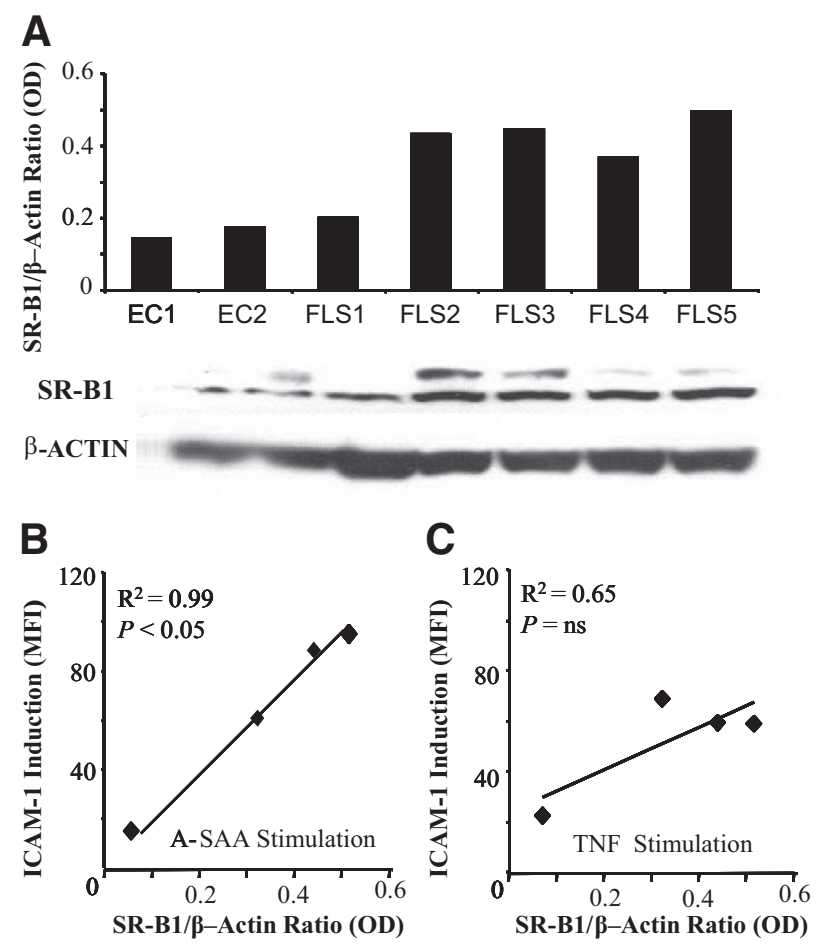

Figure 3. SR-B1 expression in RA FLCs and HMVECs. A: Representative Western blot showing SR-B1 expression in endothelial cells (ECs) and 5/5 RA FLC lines $80 \mathrm{kDa}$ molecular weight versus $\beta$-actin loading control $47 \mathrm{kDa}$. Bar graph represents quantitative SR-B1 expression by optical density (OD) relative to $\beta$-actin OD. A glycosylation band for SR-B1 is seen as previously described. ${ }^{68}$ Correlation between SR-B1 expression and ICAM-1 induction in RA FLC lines $(n=4)$ in response to $(\mathbf{B})$ A-SAA stimulation and $(\mathbf{C})$ TNF $\alpha$ expression. $\mathrm{r}=$ Spearman Rank correlation co-efficient. $P<0.05$, significant correlation between SR-B1 expression and ICAM-1 induction. SR-B1 expression was calculated before stimulation by calculating SR-B1/ actin OD ratios from Western Blots. ICAM-1 measured as Median Flourescene Intensity (MFI), which indicates the level of ICAM-1 expression on a per-cell basis.

sponsiveness to A-SAA, ICAM-I induction after A-SAA stimulation was compared with quantitative baseline SR-B1 expression on four RA FLC lines as shown in Figure 3b. Induction of ICAM-1 by A-SAA correlated closely with baseline SR-B1 expression across RA FLC lines $\left(r^{2}=0.99, P<0.05\right)$. In contrast, no significant correlation existed between ICAM-1 induction by TNF- $\alpha$ and SR-B1 expression ( $r^{2}=0.65$, Figure $\left.3 c\right)$. This suggests that the higher SR-B1 expression in primary cells may predict increased responsiveness to A-SAA.

\section{A-SAA-Induced IL-6 and IL-8 Production Is Inhibited by Anti-SR-B1 in HMVECs and RA FLCs}

To establish whether a specific antibody SR-B1 could interfere with A-SAA-induced IL-6 and IL-8 production, a further four primary RA FLC lines along with HMVECs were incubated with A-SAA in the presence or absence of anti-SR-B1. Figure 4, A and B demonstrates that A-SAA-induced IL-6 and IL-8 production were significantly inhibited in the presence of anti-SR-B1 $(P<$ 0.05). No inhibition of A-SAA effects on IL-6 and IL-8 
A

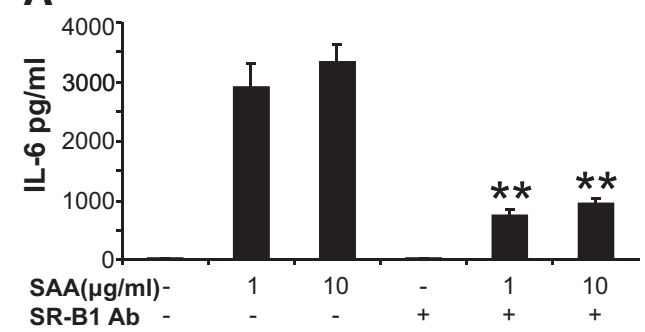

B
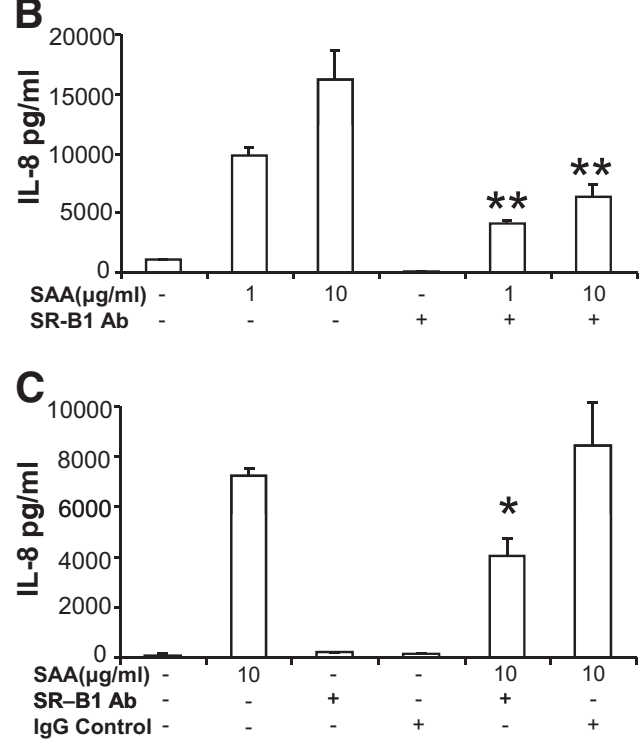

Figure 4. Blockade of A-SAA-induced ICAM-1 on HMVECs by specific anti-SR-B1 antibody. HMVECs $(n=3)$ were stimulated with A-SAA for 24 hours (1 to $10 \mu \mathrm{g} / \mathrm{ml})$ in the presence or absence of anti-SR-B1 $(10 \mu \mathrm{g} / \mathrm{ml})$ antibody or IgG control antibody $(10 \mu \mathrm{g} / \mathrm{ml})$. A-SAA dependent (A) IL-6 and (B) IL-8 production is significantly inhibited by co-incubation with antiSR-B1 $\left(n=6,{ }^{* * *} P<0.05\right)$. C: Representative bar graph demonstrating that co-incubation of isotype IgG1 control antibody with A-SAA does not inhibit IL-8 production. ( ${ }^{*} P<0.01$, significant reduction in IL-8 secretion by antiSR-B1 compared to IgG1 control).

production by isometric control IgG1 in HMVECs was observed (Figure 4C).

Figure 5, A-D demonstrates the effect of anti-SR-B1 on A-SAA-induced IL-6 and IL-8 expression in four different primary RA FLC lines. Incubation with anti-SR-B1 inhibits A-SAA-induced IL-6 production in three primary RA FLCs (Figure 5, A-C), with no effect in the fourth primary $R A$ FLC line. A-SAA-induced IL-8 production in three of four RASFC lines. In the three RA FLC lines that responded to A-SAA, incubation with anti-SR-B1 inhibited IL-8 production in two RA FLC lines ( $A$ and $B$ ), with no effect observed in the fourth primary RA FLC line as observed was observed for IL-6. This suggests that SR-B1 mediates both A-SAA-induced IL-6 and IL-8 production, however in comparison with the HMVECs where A-SAA induction and inhibition with anti-CLA-I was consistent, results differed between primary RA FLC lines reflecting the heterogeneity of patients. This is consistent with the immunohistochemistry findings, where two of the eight RA patients had no expression of SR-B1, suggesting it may mediate A-SAA pro-inflammatory effects on some patients but not all.
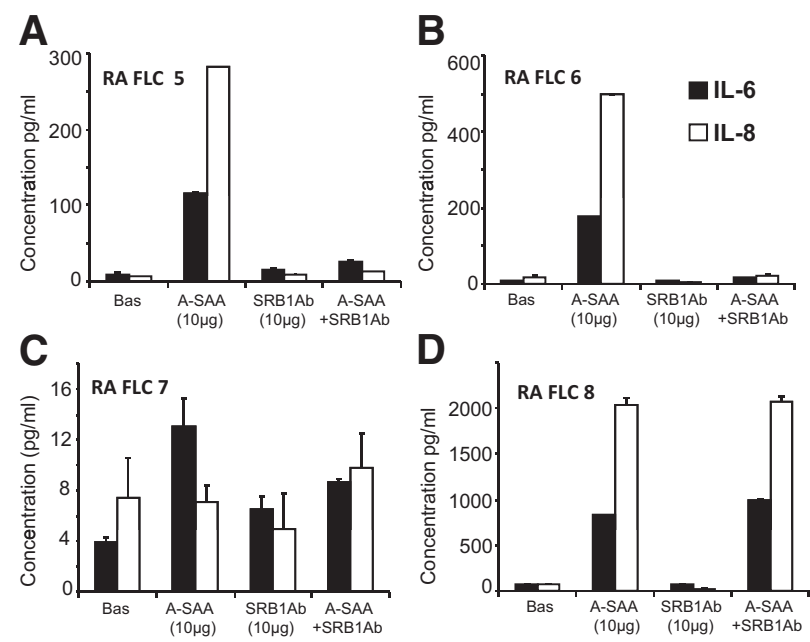

Figure 5. Blockade of A-SAA-induced ICAM-1 on RA FLCs by specific anti-SR-B1 antibody. Four separate primary RA FLC lines stimulated for 24 hours in duplicate with A-SAA $(10 \mu \mathrm{g} / \mathrm{ml})$ in the presence or absence of anti-SR-B1antibody $(10 \mu \mathrm{g} / \mathrm{ml})$. A-C: Inhibition of A-SAA-induced IL-6 by anti-SR-B1 antibody was seen in three of four cell lines. $\mathbf{A}$ and $\mathbf{B}$ : Inhibition of A-SAA-induced IL- 8 by anti-SR-B1 antibody was seen in two of four cell lines. D: No effect by anti-SR-B1 on A-SAA induced IL-6 or IL-8 was seen in one of four cell lines. Results represent mean \pm SE results from four distinct RA FLC line experiments performed in duplicate.

\section{Amphipathic $\alpha$-Helical Peptides Inhibit A-SAA-Induced VCAM-1 and ICAM-1 Expression}

The effects of the amphipathic $\alpha$-helical peptides D-37pA and L-37pA on A-SAA-induced cell surface expression of VCAM- 1 on HMVECs are shown in Figure 6. A-SAA 0.5 $\mu \mathrm{g} / \mathrm{ml}$ stimulation for 6 hours significantly increased VCAM- 1 from $20+0.8 \%$ to $82+17 \%$ of cells. Coincubation of cells with both A-SAA $0.5 \mu \mathrm{g} / \mathrm{ml}$ and L-37pA $5 \mu \mathrm{g} / \mathrm{ml}$ significantly inhibited the induction of VCAM-1 expression to $25+5 \%$ cells $(P<0.001$, Figure $6 a)$. Co-incubation of cells with both A-SAA $0.5 \mu \mathrm{g} / \mathrm{ml}$ and D-37pA $5 \mu \mathrm{g} / \mathrm{ml}$ significantly inhibited the induction of VCAM-1 expression to $27+5 \%$ cells $(P=0.002$, Figure $6 B)$. In contrast, co-incubation of HMVECs with A-SAA and the control scrambled peptide L3D-37pA did not attenuate the response of HMVECs to A-SAA (Figure 6c). A dose-dependent inhibition of A-SAA-induced VCAM-1 expression on HMVECs by both D-37pA and L-37pA was demonstrated when used at both 10- and 20-fold excess. No dose-dependent inhibition was seen with the control peptide L3D-37pA (Figure 6D). A-SAA $0.5 \mu \mathrm{g} / \mathrm{ml}$ stimulation for 6 hours significantly increased ICAM-1 from $63+0.8 \%$ to $90+0.7 \%$ of cells. Co-incubation of cells with both A-SAA $0.5 \mu \mathrm{g} / \mathrm{ml}$ and L-37pA $5 \mu \mathrm{g} / \mathrm{ml}$ significantly inhibited the induction of ICAM-1 expression to $76+0.7 \%$ cells $(P<0.001$, Figure $6 \mathrm{E})$. Co-incubation of cells with both A-SAA $0.5 \mu \mathrm{g} / \mathrm{ml}$ and D-37pA $5 \mu \mathrm{g} / \mathrm{ml}$ significantly inhibited the induction of ICAM-1 expression to $80+0.9 \%$ cells $(P=0.02$, Figure $6 \mathrm{~F})$.

\section{Discussion}

RA is a chronic progressive autoimmune disease characterized by proliferation of synovial membrane with deg- 
A
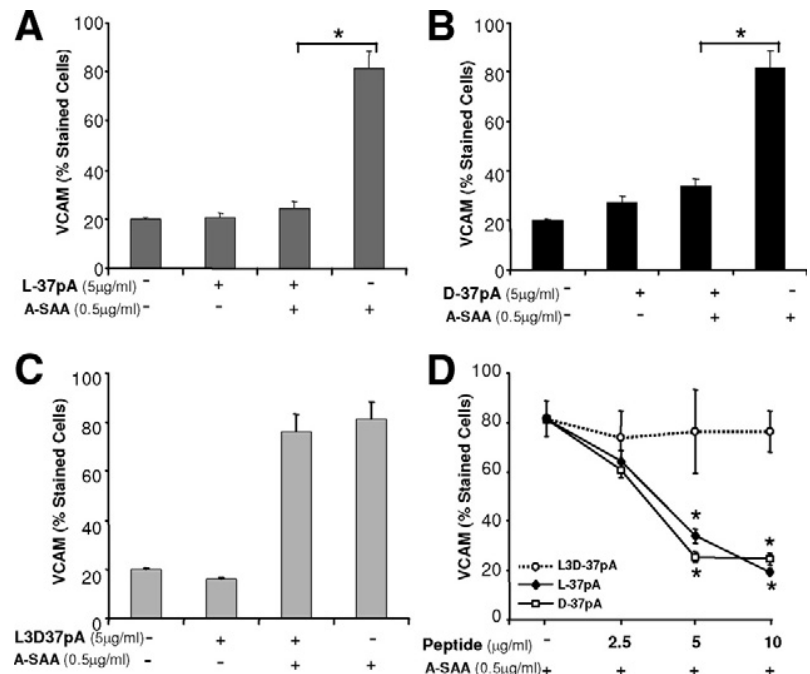

E
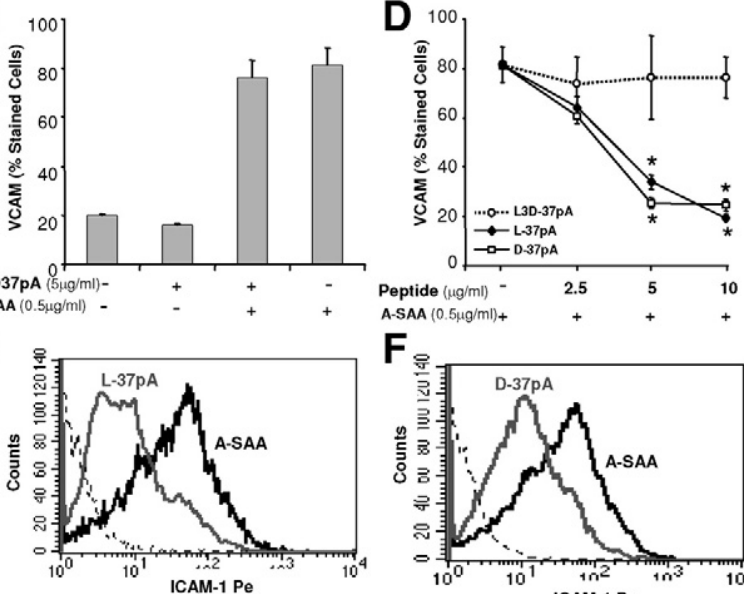

$\mathbf{F}$

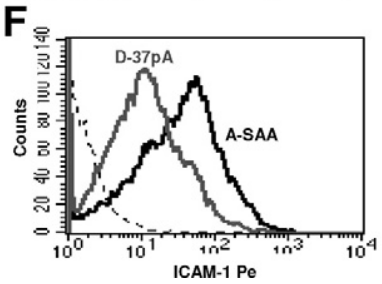

Figure 6. Synthetic mimetic peptides of ApoA-1 block A-SAA-induced VCAM-1 and ICAM-1 on HMVECs. HMVECs were incubated with A-SAA in the presence of increasing peptide concentrations. A-D: ApoA-1 mimetic peptides L-37pA $(5 \mu \mathrm{g} / \mathrm{ml})$ and D-37pA $(5 \mu \mathrm{g} / \mathrm{ml})$ or scrambled peptide control L3 days-37pA $(5 \mu \mathrm{g} / \mathrm{ml})$. A statistically significant dose-dependent inhibition of A-SAA-induced VCAM-1 was seen using L-37pA and D-37pA Results represent mean \pm SD results from six separate HMVEC experiments performed in duplicate, ${ }^{*} P<0.05$. E and $\mathbf{F}$ : Representative FACS histograms demonstrating down-regulation of $0.5 \mu \mathrm{g} / \mathrm{ml} \mathrm{A}$-SAA-induced ICAM-1 expression by L-37pA and D-37pA. Flourescence levels obtained using IgG control antibody are shown by dashed line.

radation of articular cartilage and subchondral bone. RA affects approximately $2 \%$ of the population and is associated with a significant increase in cardiovascular disease. Normal SM consists of a monolayer of synovial fibroblast and macrophages, which produce a proteoglycan rich synovial fluid that lubricates the joint. However in $\mathrm{RA}$, activation of the SM transforms the lining layer into a hyperplastic tumor-like 'pannus' composed primarily of activated FLCs, macrophage-like synoviocytes, and lymphocytes, which through self perpetuating and persistent pro-inflammatory activation, are capable of destroying adjacent articular cartilage and bone.

A-SAA is a highly conserved acute phase protein implicated in a wide range of physiological and pathophysiological processes involving inflammation. A-SAA is produced as a normal component of the inflammatory response during trauma and infection in both vertebrate and non vertebrate species. ${ }^{34-38}$ A-SAA has been shown to have pro-inflammatory effects similar to cytokines $^{20,39-45}$ and has been implicated in a wide range of pathological processes including arthritis, bowel disease, malignancy, atherosclerosis, the metabolic syndrome, and type II diabetes. ${ }^{46-50}$ We have previously demonstrated that A-SAA promotes angiogenesis, leukocyte recruitment, and matrix degradation, ${ }^{17}$ key processes in the pathogenesis of RA. It is known that
FRPL-1/LXA4R protein mediates the pro-inflammatory effects of A-SAA, however recent evidence demonstrates that A-SAA is a potent ligand for SR-B1. ${ }^{23}$ Together these studies provide strong evidence for an important regulatory role of A-SAA in inflammation and in the immune response.

The current study demonstrates expression of the SR-B1 scavenger receptor in the inflamed synovial membrane of RA joints, with expression lower in patients with inflammatory OA. In particular, we have demonstrated strong expression of SR-B1 on the synovial vascular endothelium, and the hyperplastic lining layer at the leading edge of the synovial pannus, which invades articular cartilage and bone. Furthermore, using Western blot and immunoflourescent microscopy we confirm the expression of SR-B1 on both primary RA FLCs and HMVECs. This pattern of expression of SR-B1 corresponds closely with results of our previous work, which demonstrated expression of A-SAA in a similar histological distribution. To elucidate the extent to which SR-B1 expression relates to A-SAA responsiveness, A-SAA-induced ICAM-1 was correlated with baseline SR-B1 expression. The linear correlation between these variables suggest that the level of SR-B1 expression is an important determinant of ASAA-induced pro-inflammatory responses in RA FLCs and HMVECs. In contrast, no significant correlation was found between SR-B1- and TNF- $\alpha$-induced ICAM-1 expression, suggesting that the A-SAA/SR-B1 effect is specific and not merely a marker of cell responsiveness to general pro-inflammatory stimuli. This observation is further supported by Baranova et al, who demonstrated direct A-SAA/SR-B1 binding in human monocyte cells and showed that SR-B1-overexpressing HeLa cells correlated with higher IL-8 production compared with control cells. ${ }^{23}$

The FPRL-1 receptor has been implicated as the specific receptor mediating the effects of A-SAA in several cell types, however we demonstrate in primary human $R A$ synovial cells for the first time that A-SAA may function through an alternative pathway via SR-B1. To date a direct role for SR-B1 in mediating A-SAA-induced proinflammatory effects has not been examined in RA FLCs or HMVECs. To examine this functional relationship we used a specific monoclonal antibody to the SR-B1 receptor. A HMVEC line and four separate primary RA FLC lines were stimulated with A-SAA in the presence or absence of anti-SR-B1, which significantly inhibited ASAA-induced IL-6 and IL-8 production. Finally, D-37pA and $L-37 p A$, which are homologous to the amphipathic $\alpha$ helical region of ApoA-1 (antagonists of SR-B1), inhibited A-SAA-induced adhesion molecule (ICAM-1 and VCAM-1) expression on the HMVEC line. ApoA-1 has previously been shown to be anti-inflammatory by preventing IL- $1 \beta$ and TNF- $\alpha$ secretion from monocytes cells though inhibition of contact mediated activation by $T$ lymphocytes. ${ }^{51}$ The ApoA-1 mimetic peptide L-37PA acts as a ligand for SR-B1, where it has been shown to block the pro-inflammatory cytokine response to LPS in THP-1 cells. ${ }^{26}$ To date, however, no direct anti-inflammatory role for ApoA-1 through interaction with SR-B1 has been demonstrated in vivo. Our observation that a specific antiSR-B1 antibody inhibits A-SAA-induced IL-6 and IL-8 
production provides further evidence that SR-B1 may be an important determinate of the innate inflammatory response in vivo. Further work investigating a broader range of pro-inflammatory responses is now required to confirm both whether other A-SAA-mediated effects occur through SR-B1 and whether the actions of the ApoA-1 mimetic peptides presented here are reflective of an immunomodulatory role for ApoA-1 in vivo.

The evidence that induction of IL-6 may result after stimulation of RA tissue with A-SAA is novel. IL-6 is a key cytokine in the circulation of patients with RA, and recently has been the focus of a new targeted biological therapy, ${ }^{52}$ IL-6 had previously been shown to be an inducer of $A-S A A,{ }^{53}$ is synthesized by lymphocytes and RA FLCs, and is detectable in inflamed synovial tissue. ${ }^{54,55}$ Reciprocal upregulation between A-SAA and IL-1 in inflammation has been reported before. ${ }^{13,44}$ Treatment with IL-1 receptor antagonist (IL-1Ra) or with a soluble IL-6 receptor (IL-6R) have both demonstrated efficacy in ameliorating the clinical course of RA. ${ }^{52,56}$ Recent evidence has demonstrated that A-SAA activates Receptor for Advanced Glycation Endproducts (RAGE) in synovial cells, resulting in activation of the NF- $\kappa \mathrm{B}$ signaling pathway. ${ }^{57}$ Furthermore, Toll-like Receptor 2 (TLR2) has recently been described as a functional receptor for A-SAA, leading to increased phosphorylation of MAPKs and degradation of $I_{\kappa} b \alpha{ }^{58}$ Together, these findings suggest an important role for A-SAA in the pro-inflammatory cascade of events, interlinked with cytokines, closely associated with synovial membrane inflammation, tissue destruction, and permanent joint damage in RA.

In addition to the well-characterized joint destruction seen in this disease, RA has a well-recognized association with significantly higher rates of cardiovascular mortality. SR-B1 overexpression has previously been demonstrated in atheromatous plaques compared with normal vascular endothelium. ${ }^{59}$ Increased cardiovascular risk has been independently associated with elevated levels of systemic inflammatory markers including ASAA. ${ }^{60}$ As part of the systemic inflammatory response A-SAA displaces ApoA-1 from HDL to become the major HDL-associated apoprotein in inflammation. ${ }^{61,62}$ In vitro studies have demonstrated that A-SAA-enriched HDL may be pro-atherogenic through a three- to fourfold higher affinity for macrophages and an increased affinity for uptake into vascular ECs when compared with unenriched HDL. ${ }^{63} \mathrm{~A}-\mathrm{SAA}$ has been implicated in a number of diseases characterized both by inflammation and increased cardiovascular mortality, including diabetes, the metabolic syndrome, malignancy, and primary cardiovascular disease ${ }^{64-67}$ It is intriguing to speculate that A-SAA/SR-B1 interactions may, in addition to a role in joint inflammation, also have a role in the long-term cardiovascular complications described in RA.

In summary, we have demonstrated for the first time the expression of the HDL receptor, SR-B1 in inflamed RA synovial tissue. We have shown that pro-inflammatory responses by A-SAA correlate closely with SR-B1 expression on RA FLCs in vitro, and that the effects of A-SAA stimulation can be down-regulated by SR-B1 antagonist mimetic peptides and a specific anti-SR-B1 antibody.
Finally, we have identified new cytokine interactions with A-SAA, which may be attenuated by blocking SR-B1. These findings suggest that modulation of inflammation through SR-B1 may provide a future therapeutic strategy for the treatment of RA and its associated cardiovascular risk.

\section{Acknowledgment}

We thank Alexander Bocharov (Department of Laboratory Medicine, W. G. Magnuson Clinical Center, NHLBI, National Institutes of Health, Bethesda, MD) for kindly supplying mimetic peptides of ApoA-1.

\section{References}

1. Koch AE: c17 Angiogenesis as a target in rheumatoid arthritis. Ann Rheum Dis 2000, 59 Suppl 1:i65-71

2. Fisher KL, Lu J, Riddle L, Kim KJ, Presta LG, Bodary SC: c17 Identification of the binding site in intercellular adhesion molecule 1 for its receptor, leukocyte function-associated antigen 1. Mol Biol Cell 1997, 8:501-515

3. Fearon U, Griosios K, Fraser A, Reece R, Emery P, Jones PF, Veale DJ: c17 Angiopoietins, growth factors, and vascular morphology in early arthritis. J Rheumatol 2003, 30:260-268

4. Cawston TE, Milner JM, Catterall JB, Rowan AD: Cytokine synergy, collagenases and cartilage collagen breakdown. Biochem Soc Symp 2003, 125-133

5. Feldmann M, Brennan FM, Chantry D, Haworth C, Turner M, Abney E, Buchan G, Barrett K, Barkley D, Chu A, et al: c17 Cytokine production in the rheumatoid joint: implications for treatment. Ann Rheum Dis 1990, 49 Suppl 1:480-486

6. Nagase $H$, Kashiwagi M: c17 Aggrecanases and cartilage matrix degradation. Arthritis Res Ther 2003, 5:94-103

7. Uhlar CM, Burgess CJ, Sharp PM, Whitehead AS: c17 Evolution of the serum amyloid A (SAA) protein superfamily. Genomics 1994, 19:228-235

8. Urieli-Shoval S, Linke RP, Matzner Y: c17 Expression and function of serum amyloid A, a major acute-phase protein, in normal and disease states. Curr Opin Hematol 2000, 7:64-69

9. Malle E, De Beer FC: c17 Human serum amyloid A (SAA) protein: a prominent acute-phase reactant for clinical practice. Eur J Clin Invest 1996, 26:427-435

10. Cabana VG, Feng N, Reardon CA, Lukens J, Webb NR, de Beer FC, Getz GS: c17 Influence of apoA-I and apoE on the formation of serum amyloid A-containing lipoproteins in vivo and in vitro. J Lipid Res 2004, 45:317-325

11. Kushner I: c17 The phenomenon of the acute phase response. Ann NY Acad Sci 1982, 389:39-48

12. Cunnane G, Grehan S, Geoghegan S, McCormack C, Shields D, Whitehead AS, Bresnihan B, Fitzgerald O: c17 Serum amyloid A in the assessment of early inflammatory arthritis. J Rheumatol 2000, 27:58-63

13. Vallon R, Freuler F, Desta-Tsedu N, Robeva A, Dawson J, Wenner P, Engelhardt P, Boes L, Schnyder J, Tschopp C, Urfer R, Baumann G: Serum amyloid A (apoSAA) expression is up-regulated in rheumatoid arthritis and induces transcription of matrix metalloproteinases. J Immunol 2001, 166:2801-2807

14. O'Hara R, Murphy EP, Whitehead AS, FitzGerald O, Bresnihan B: Local expression of the serum amyloid A and formyl peptide receptor-like 1 genes in synovial tissue is associated with matrix metalloproteinase production in patients with inflammatory arthritis. Arthritis Rheum 2004, 50:1788-1799

15. Zerega B, Pagano A, Pianezzi A, Ulivi V, Camardella L, Cancedda R, Cancedda FD: c17 Expression of serum amyloid A in chondrocytes and myoblasts differentiation and inflammation: possible role in cholesterol homeostasis. Matrix Biol 2004, 23:35-46 
16. He R, Sang H, Ye RD: Serum amyloid $A$ induces IL-8 secretion through a G protein-coupled receptor, FPRL1/LXA4R. Blood 2003, 101:1572-1581

17. Mullan RH, Bresnihan B, Golden-Mason L, Markham T, O'Hara R FitzGerald O, Veale DJ, Fearon U: c17 Acute-phase serum amyloid A stimulation of angiogenesis, leukocyte recruitment, and matrix degradation in rheumatoid arthritis through an NF-kappaB-dependent signal transduction pathway. Arthritis Rheum 2006, 54:105-114

18. Preciado-Patt L, Hershkoviz R, Fridkin M, Lider O: c17 Serum amyloid A binds specific extracellular matrix glycoproteins and induces the adhesion of resting CD4+ T cells. J Immunol 1996, 156:1189-1195

19. Hershkoviz R, Preciado-Patt L, Lider O, Fridkin M, Dastych J, Metcalfe DD, Mekori YA: Extracellular matrix-anchored serum amyloid A preferentially induces mast cell adhesion. Am J Physiol 1997 273:C179-C187

20. Xu L, Badolato R, Murphy WJ, Longo DL, Anver M, Hale S, Oppenheim $\mathrm{JJ}$, Wang JM: A novel biologic function of serum amyloid A. Induction of T lymphocyte migration and adhesion. J Immunol 1995, 155:1184-1190

21. Migita K, Kawabe Y, Tominaga M, Origuchi T, Aoyagi T, Eguchi K: Serum amyloid A protein induces production of matrix metalloproteinases by human synovial fibroblasts. Lab Invest 1998, 78:535-539

22. Sodin-Semrl S, Spagnolo A, Mikus R, Barbaro B, Varga J, Fiore S: c17 Opposing regulation of interleukin-8 and NF-kappaB responses by lipoxin A4 and serum amyloid A via the common lipoxin A receptor. Int J Immunopathol Pharmacol 2004, 17:145-156

23. Baranova IN, Vishnyakova TG, Bocharov AV, Kurlander R, Chen Z, Kimelman ML, Remaley AT, Csako G, Thomas F, Eggerman TL, Patterson AP: Serum amyloid A binding to CLA-1 (CD36 and LIMPI analogous-1) mediates serum amyloid A protein-induced activation of ERK $1 / 2$ and p38 mitogen-activated protein kinases. J Biol Chem 2005, 280:8031-8040

24. Babitt J, Trigatti B, Rigotti A, Smart EJ, Anderson RG, Xu S, Krieger M: Murine SR-BI, a high density lipoprotein receptor that mediates selective lipid uptake, is N-glycosylated and fatty acylated and colocalizes with plasma membrane caveolae. J Biol Chem 1997, 272 $13242-13249$

25. van der Westhuyzen DR, Cai L, de Beer MC, de Beer FC: Serum amyloid A promotes cholesterol efflux mediated by scavenger receptor B-I. J Biol Chem 2005, 280:35890-35895

26. Bocharov AV, Baranova IN, Vishnyakova TG, Remaley AT, Csako G, Thomas F, Patterson AP, Eggerman TL: Targeting of scavenger receptor class B type I by synthetic amphipathic alpha-helical-containing peptides blocks lipopolysaccharide (LPS) uptake and LPS-induced pro-inflammatory cytokine responses in THP-1 monocyte cells. J Biol Chem 2004, 279:36072-36082

27. Arnett FC, Edworthy SM, Bloch DA, McShane DJ, Fries JF, Coope NS, Healey LA, Kaplan SR, Liang MH, Luthra HS, et al: c17 The American Rheumatism Association 1987 revised criteria for the classification of rheumatoid arthritis. Arthritis Rheum 1988, 31:315-324

28. Kruithof E, De Rycke L, Vandooren B, De Keyser F, FitzGerald O, McInnes I, Tak PP, Bresnihan B, Veys EM, Baeten D: Identification of synovial biomarkers of response to experimental treatment in early-phase clinical trials in spondylarthritis. Arthritis Rheum 2006 54:1795-1804

29. Rooney T, Bresnihan B, Andersson U, Gogarty M, Kraan M, Schumacher HR, Ulfgren AK, Veale DJ, Youssef PP, Tak PP: Microscopic measurement of inflammation in synovial tissue: inter-observer agreement for manual quantitative, semiquantitative and computerised digital image analysis. Ann Rheum Dis 2007, 66:1656-1660

30. Fairwell T, Hospattankar AV, Brewer HB Jr, Khan SA: Human plasma apolipoprotein C-II: total solid-phase synthesis and chemical and biological characterization. Proc Natl Acad Sci USA 1987, 84: $4796-4800$

31. Remaley AT, Thomas F, Stonik JA, Demosky SJ, Bark SE, Neufeld EB, Bocharov AV, Vishnyakova TG, Patterson AP, Eggerman TL, Santamarina-Fojo S, Brewer HB: c17 Synthetic amphipathic helical peptides promote lipid efflux from cells by an ABCA1-dependent and an ABCA1-independent pathway. J Lipid Res 2003, 44:828-836

32. Tolboom TC, van der Helm-Van Mil AH, Nelissen RG, Breedveld FC, Toes RE, Huizinga TW: Invasiveness of fibroblast-like synoviocytes is an individual patient characteristic associated with the rate of joint destruction in patients with rheumatoid arthritis. Arthritis Rheum 2005 52:1999-2002

33. Seemayer CA, Kuchen S, Kuenzler P, Rihoskova V, Rethage J, Aicher
WK, Michel BA, Gay RE, Kyburz D, Neidhart M, Gay S: Cartilage destruction mediated by synovial fibroblasts does not depend on proliferation in rheumatoid arthritis. Am J Pathol 2003, 162:1549-1557

34. Arnon S, Litmanovitz I, Regev RH, Bauer S, Shainkin-Kestenbaum R, Dolfin T: c17 Serum amyloid A: An early and accurate marker of neonatal early-onset sepsis. J Perinatol 2007, 27:297-302

35. Gruber AD, Linke RP: $c 17$ Generalised AA-amyloidosis in a bat (Pipistrellus pipistrellus). Vet Pathol1996, 33:428-430

36. Mozes G, Friedman N, Shainkin-Kestenbaum R: c17 Serum amyloid $A$ : an extremely sensitive marker for intensity of tissue damage in trauma patients and indicator of acute response in various diseases. J Trauma 1989, 29:71-74

37. Santiago P, Roig-Lopez JL, Santiago C, Garcia-Arraras JE: C17 Serum amyloid $A$ protein in an echinoderm: its primary structure and expression during intestinal regeneration in the sea cucumber Holothuria glaberrima. J Exp Zool 2000, 288:335-344

38. Santiago-Cardona PG, Berrios CA, Ramirez F, Garcia-Arraras JE: c17 Lipopolysaccharides induce intestinal serum amyloid $A$ expression in the sea cucumber Holothuria glaberrima. Dev Comp Immunol 2003, 27:105-110

39. Badolato R, Wang JM, Murphy WJ, Lloyd AR, Michiel DF, Bausserman LL, Kelvin DJ, Oppenheim JJ: c17 Serum amyloid A is a chemoattractant: induction of migration, adhesion, and tissue infiltration of monocytes and polymorphonuclear leukocytes. J Exp Med 1994 180:203-209

40. Badolato R, Wang JM, Stornello SL, Ponzi AN, Duse M, Musso T: c17 Serum amyloid $\mathrm{A}$ is an activator of PMN antimicrobial functions: induction of degranulation, phagocytosis, and enhancement of antiCandida activity. J Leukoc Biol 2000, 67:381-386

41. Furlaneto $C J$, Campa $A: A$ novel function of serum amyloid $A: A$ potent stimulus for the release of tumor necrosis factor-alpha, interleukin-1beta, and interleukin-8 by human blood neutrophil. Biochem Biophys Res Commun 2000, 268:405-408

42. Hatanaka E, Furlaneto CJ, Ribeiro FP, Souza GM, Campa A: c17 Serum amyloid A-induced mRNA expression and release of tumor necrosis factor-alpha (TNF-alpha) in human neutrophils. Immunol Lett 2004, 91:33-37

43. Kumon $Y$, Hosokawa $T$, Suehiro $T$, Ikeda $Y$, Sipe JD, Hashimoto $K$ : c17 Acute-phase, but not constitutive serum amyloid A (SAA) is chemotactic for cultured human aortic smooth muscle cells. Amyloid 2002, 9:237-241

44. Patel H, Fellowes R, Coade S, Woo P: c17 Human serum amyloid A has cytokine-like properties. Scand J Immunol 1998, 48:410-418

45. Ribeiro FP, Furlaneto CJ, Hatanaka E, Ribeiro WB, Souza GM, Cassatella MA, Campa A: c17 mRNA expression and release of interleukin- 8 induced by serum amyloid $A$ in neutrophils and monocytes. Mediators Inflamm 2003, 12:173-178

46. Kumon Y, Suehiro T, Itahara T, Ikeda Y, Hashimoto K: c17 Serum amyloid A protein in patients with non-insulin-dependent diabetes mellitus. Clin Biochem 1994, 27:469-473

47. Morrow DA, Rifai N, Antman EM, Weiner DL, McCabe CH, Cannon $\mathrm{CP}$, Braunwald E: $\mathrm{c} 17$ Serum amyloid A predicts early mortality in acute coronary syndromes: A TIMI 11A substudy. J Am Coll Cardiol 2000, 35:358-362

48. Niederau C, Backmerhoff F, Schumacher B, Niederau C: c17 Inflammatory mediators and acute phase proteins in patients with Crohn's disease and ulcerative colitis. Hepato-gastroenterology 1997, 44:90-107

49. Weinstein PS, Skinner M, Sipe JD, Lokich JJ, Zamcheck N, Cohen AS c17 Acute-phase proteins or tumour markers: the role of SAA, SAP CRP and CEA as indicators of metastasis in a broad spectrum of neoplastic diseases. Scand J Immunol 1984, 19:193-198

50. Yang RZ, Lee MJ, Hu H, Pollin TI, Ryan AS, Nicklas BJ, Snitker S, Horenstein RB, Hull K, Goldberg NH, Goldberg AP, Shuldiner AR, Fried SK, Gong DW: Acute-phase serum amyloid A: an inflammatory adipokine and potential link between obesity and its metabolic complications. PLoS Med 2006, 3:e287

51. Hyka N, Dayer JM, Modoux C, Kohno T, Edwards CK, 3rd, RouxLombard P. Burger D: Apolipoprotein A-I inhibits the production of interleukin-1beta and tumor necrosis factor-alpha by blocking contact-mediated activation of monocytes by T lymphocytes. Blood 2001, 97:2381-2389

52. Nishimoto N, Yoshizaki K, Miyasaka N, Yamamoto K, Kawai S, Takeuchi T, Hashimoto J, Azuma J, Kishimoto T: Treatment of rheumatoid arthritis 
with humanized anti-interleukin-6 receptor antibody: a multicenter, double-blind, placebo-controlled trial. Arthritis Rheum 2004, 50:1761-1769

53. Hagihara K, Nishikawa T, Isobe T, Song J, Sugamata Y, Yoshizaki K: IL-6 plays a critical role in the synergistic induction of human serum amyloid A (SAA) gene when stimulated with proinflammatory cytokines as analyzed with an SAA isoform real-time quantitative RT-PCR assay system. Biochem Biophys Res Commun 2004, 314:363-369

54. Asquith DL, McInnes IB: c17 Emerging cytokine targets in rheumatoid arthritis. Curr Opin Rheumatol 2007, 19:246-251

55. Smeets TJ, Barg EC, Kraan MC, Smith MD, Breedveld FC, Tak PP: c17 Analysis of the cell infiltrate and expression of proinflammatory cytokines and matrix metalloproteinases in arthroscopic synovial biopsies: comparison with synovial samples from patients with end stage, destructive rheumatoid arthritis. Ann Rheum Dis 2003, 62: 635-638

56. Bresnihan B, Alvaro-Gracia JM, Cobby M, Doherty M, Domljan Z, Emery P, Nuki G, Pavelka K, Rau R, Rozman B, Watt I, Williams B, Aitchison R, McCabe D, Musikic P: Treatment of rheumatoid arthritis with recombinant human interleukin-1 receptor antagonist. Arthritis Rheum 1998, 41:2196-2204

57. Okamoto H, Katagiri Y, Kiire A, Momohara S, Kamatani N: c17 Serum amyloid $\mathrm{A}$ activates nuclear factor-kappaB in rheumatoid synovial fibroblasts through binding to receptor of advanced glycation endproducts. J Rheumatol 2008, 35:752-756

58. Cheng N, He R, Tian J, Ye PP, Ye RD: Cutting edge: TLR2 is a functional receptor for acute-phase serum amyloid A. J Immunol 2008, 181:22-26

59. Forcheron F, Legedz L, Chinetti G, Feugier P, Letexier D, Bricca G, Beylot M: c17 Genes of cholesterol metabolism in human atheroma: overexpression of perilipin and genes promoting cholesterol storage and repression of ABCA1 expression. Arterioscler Thromb Vasc Biol 2005, 25:1711-1717

60. Johnson BD, Kip KE, Marroquin OC, Ridker PM, Kelsey SF, Shaw LJ,
Pepine CJ, Sharaf B, Bairey Merz CN, Sopko G, Olson MB, Reis SE: Serum amyloid $\mathrm{A}$ as a predictor of coronary artery disease and cardiovascular outcome in women: the National Heart, Lung, and Blood Institute-Sponsored Women's Ischemia Syndrome Evaluation (WISE). Circulation 2004, 109:726-732

61. Hoffman JS, Benditt EP. J Biol Chem 1982, 257:10518-10522

62. Lindhorst E, Young D, Bagshaw W, Hyland M, Kisilevsky R: Acute inflammation, acute phase serum amyloid $A$ and cholesterol metabolism in the mouse. Biochim Biophys Acta 1997,1339:143-154

63. Hayat S, Raynes JG: c17 Acute phase serum amyloid A protein increases high density lipoprotein binding to human peripheral blood mononuclear cells and an endothelial cell line. Scand J Immunol 2000, 51:141-146

64. Delanghe JR, Langlois MR, De Bacquer D, Mak R, Capel P, Van Renterghem L, De Backer G: c17 Discriminative value of serum amyloid $\mathrm{A}$ and other acute-phase proteins for coronary heart disease. Atherosclerosis 2002, 160:471-476

65. Jernas M, Palming J, Sjoholm K, Jennische E, Svensson PA, Gabrielsson BG, Levin M, Sjogren A, Rudemo M, Lystig TC, Carlsson B, Carlsson LM, Lonn M: Separation of human adipocytes by size: hypertrophic fat cells display distinct gene expression. FASEB J 2006, 20:1540-1542

66. Salas-Salvado J, Bullo M, Garcia-Lorda P, Figueredo R, Del Castillo D, Bonada A, Balanza R: Subcutaneous adipose tissue cytokine production is not responsible for the restoration of systemic inflammation markers during weight loss. Int J Obes (Lond) 2006, 30:1714-1720

67. Chan DC, Chen CJ, Chu HC, Chang WK, Yu JC, Chen YJ, Wen LL, Huang SC, Ku CH, Liu YC, Chen JH: c17 Evaluation of serum amyloid A as a biomarker for gastric cancer. Ann Surg Oncol 2007, 14:84-93

68. Calvo D, Gomez-Coronado D, Lasuncion MA, Vega MA: CLA-1 is an 85-kD plasma membrane glycoprotein that acts as a high-affinity receptor for both native (HDL, LDL, and VLDL) and modified (OxLDL and AcLDL) lipoproteins. Arterioscler Thromb Vasc Biol 1997, $17: 2341-2349$ 